\title{
Almanac 2013: heart failure
}

\section{The national society journals present selected research that has driven recent advances in clinical} cardiology.

The article was first published in Heart 2013;99:21 1562-1566 Published Online First: 30 August 2013 doi:10.1136/heartjnl-2013-304761, and is republished with permission.

\section{Andrew L Clark}

${ }^{1}$ Duke-NUS Graduate Medical School, Singapore, Singapore, ${ }^{2}$ Gleneagles Hospital, Singapore, Singapore

\section{Epidemiology, The National Audit and Guidelines}

T

he National Heart Failure Audit continues to be an invaluable resource for understanding how acute heart failure is managed in England and Wales. The most recent report1 describes just over 37000 hospitalisations. As in previous publications, fewer than half the patients were managed in cardiology wards, yet those who were had a better outcome; half were referred at discharge to cardiologists for follow-up and they, too, had a better outcome. An innovation in the audit this time was the publication of hospital level analysis. It would be invidious to pick out names, but it is very striking how variable are the rates of such basic items as the use of echocardiography, availability of a cardiologist to manage the patients and the rate of prescription of different drugs.

Studies show that, during long-term follow-up, patients managed by heart failure specialists including 'heart failure nurses' are more likely to be treated with the appropriate medication in the appropriate dose, have lower (re-)admission rates to hospital and a better prognosis. ${ }^{2}$ There is reasonable evidence that there are better outcomes if part of the multidisciplinary intervention is made in the home. ${ }^{3}$ There is strong evidence that specialist clinics reduce the risk of readmission with heart failure immediately after an index admission. ${ }^{4}$ Also available to the clinician are the heart failure guidelines from the National Institute for Health and Care Excellence (NICE) ${ }^{5} 6$ and the associated quality standards. ${ }^{7}$ The NICE standards make it clear what NHS services across England and Wales should be striving towards. Combined with the hospital level analysis from the audit, the quality standards should give clinical teams the ammunition they need when discussing their heart failure service with management teams in both primary and secondary care.

However, it is becoming ever clearer that the systems used for managing heart failure at present are unlikely to be adequate in future: a study from the USA ${ }^{8}$ predicts that the costs of managing heart failure will more than double by 2030, mainly due to the ageing of the population. The capacity of the health service to accommodate the increasing numbers is not infinite. Part of the solution will surely have to be a change towards greater efficiency of use of limited resources, but reducing the risk of developing heart failure will also be a major contributor. Of some relief to many doctors, coffee appears to offer some protection! ${ }^{9}$

The latest guidelines from the European Society of Cardiology were published in 2012, merging the management of acute and chronic heart failure. ${ }^{10}$ They continue to emphasise the central role of natriuretic peptide testing for diagnosis - which is still not universally available in the UK but a key part of the NICE recommendations. The guidelines emphasise that mineralocorticoid receptor antagonists should now be considered to be part of standard therapy for anyone with symptomatic heart failure and should be used in preference to angiotensin receptor blockers as add-on therapy ACE inhibitors and $\beta$ blockers.

\section{Acute Heart Failure}

For many years the focus of heart failure research has been on patients with chronic stable heart failure. There has been little new for acute heart failure for many years. Recruiting patients with acute heart failure is difficult: they present acutely, often in the middle of the night, and are often extremely unwell. However, clinical trials are now reporting which are starting to challenge the 'standard' management of acute heart failure.

Common precipitants of an admission to hospital with heart failure include intercurrent illness, an ischaemic event or an arrhythmia. Lists of precipitants often quote 'environment' without specifying further what that might mean; but now we have some hard evidence. In a meta-analysis, Shah and colleagues ${ }^{11}$ found very strong relations between the risk of both hospitalisation for heart failure and

death and many environmental pollutants including carbon monoxide, sulfur dioxide, nitrogen dioxide and particulate matter. There is a clear public health interest in reducing environmental pollution, and we can now see the economic consequences of pollution in terms of heart failure admissions. 


\section{Fluid management}

Data from the national audit suggest that around half of patients admitted to hospital with heart failure have moderate or severe fluid retention. Traditional management has been by fluid restriction (often with salt restriction), but there is remarkably little evidence to show that this treatment is effective. In a small but intriguing study, Aliti et al ${ }^{12}$ randomised 75 patients to a radical fluidrestricted ( $800 \mathrm{~mL} /$ day) and sodium-restricted ( $800 \mathrm{mg} /$ day) regime versus no such restriction. There was no effect of the restricted diet on clinical outcomes ( particularly weight loss and readmission rates at 30 days), but the fluid restriction led to greater thirst. While this is certainly not definitive evidence, it does challenge standard practice and should lead to larger trials.

The standard therapy for fluid retention is intravenous diuretic use, often using infusions over several days. It might be possible to use ultrafiltration to remove fluid more rapidly, and an early trial of 200 patients suggested that ultrafiltration might reduce the need for emergency attendances with heart failure up to 3 months after discharge compared with standard therapy. ${ }^{13}$ In CARRESS-HF, however, the effects of ultrafiltration in 188 patients with the combination of fluid retention due to heart failure and worsening renal failure were studied. The primary endpoint was creatinine and weight loss at 96 h. Perhaps surprisingly, renal function deteriorated more in the ultrafiltration group than with standard therapy. There was no difference between the groups in either mortality or 90-day readmission rate. It is difficult to know how to interpret these data. The patients in CARESS-HF differed from those in UNLOAD, being at much higher risk because of their renal failure at baseline. Despite the patients at trial entry having 'persistent congestion' and worsening renal function (mean creatinine at trial entry $180 \mu \mathrm{mol} / \mathrm{L}$ ), those randomised to standard therapy lost over $4 \mathrm{~kg}$ in weight with no change in creatinine at $96 \mathrm{~h}$. Those randomised to ultrafiltration had a similar weight loss. It may simply be that the rise in creatinine of around $20 \mu \mathrm{mol} / \mathrm{L}$ with ultrafiltration represented haemoconcentration rather than reflecting any significant change in renal function. Ultrafiltration holds out the hope of more rapid removal of fluid for patients with heart failure (the median length of stay for fluid retention remains around 11 days), but its precise role has still not been defined.

\section{Relaxin}

There has been much excitement about serelaxin, human recombinant relaxin-2. Relaxin is mainly known for its effect in pregnancy, but it causes arterial vasodilation with little effect on venodilation. A small dose-finding trial suggested that it might lead to more rapid relief of breathlessness in patients with acute heart failure, with a suggestion that it might improve outcome. ${ }^{14}$ In the RELAX-AHF trial, ${ }^{15} 1161$ patients with acute heart failure were randomised to receive $48 \mathrm{~h}$ infusions of placebo or serelaxin. The serelaxin-treated patients had a modest improvement in their breathlessness, but only in one of the two scales used. More interestingly, though, there was a reduction in mortality at 6 months in the serelaxin group compared with placebo.

How this will translate into clinical practice is not at all clear. Although the Food and Drug Administration in the USA has given serelaxin 'Breakthrough Therapy' designation, ${ }^{16}$ suggesting that they believe serelaxin represents 'a substantial improvement over currently available therapies', the data from RELAX-AHF are not convincing. There were only a small number of events, serelaxin appeared to have no effect on other events, and the comparator limb of the trial was placebo (and not another vasodilator such as a nitrate). Nevertheless, if the results are confirmed in further trials, serelaxin may represent the first major step forward in treating acute heart failure in many years.

\section{Neprilysin inhibition}

LCZ696 is the first in a new class of drugs termed ARNIs - that is, a combined angiotensin II receptor antagonist (valsartan) with a neprilysin inhibitor. Neprilysin is the enzyme responsible for the breakdown of natriuretic peptides, so its blockade increases the amount of natriuretic peptide in the circulation. In the PARAMOUNT trial, ${ }^{17} 301$ patients with heart failure and a normal ejection fraction were randomised to receive the combined inhibitor or valsartan alone. Those receiving LCZ696 had a greater decline in $\mathrm{N}$-terminal prohormone of brain natriuretic peptide at 12 weeks (an effect lost by 36 weeks), and there was greater improvement in symptoms. The positive results will probably trigger a large outcome study, although there will be problems in knowing what the comparator to LCZ might be. ${ }^{18}$

\section{Levosimendan}

The REVIVE studies testing the effects of levosimendan in patients with acute heart failure have finally been published, around 8 years after they were first presented. ${ }^{19}$ Levosimendan is a calcium sensitising drug - it has inotropic and vasodilator effects. There was much initial enthusiasm over its possible role in acute heart failure and, in REVIVE, there was a greater likelihood of clinical improvement with levosimendan. However, there was an increased risk of death, albeit non-significant, in the levosimendan group.

The delay in publication highlights a very important issue in clinical trials - namely, that neutral or negative trials might go unreported. Levosimendan has been widely available in Europe, but its potentially deleterious effects may not be recognised by those using it. Those designing and running clinical trials have a moral obligation to publish their data: patients have, after all, agreed to take part in clinical trials on the basis that the results may benefit others. ${ }^{20}$

\section{Chronic Heart Failure}

\section{Ivabradine}

The SHIFT study ${ }^{21}$ suggested that the addition of ivabradine, which slows the heart rate by inhibiting sinus 
node depolarisation, improves outcomes in patients with heart failure due to left ventricular systolic dysfunction, in sinus rhythm and with a heart rate $\geq 70 / \mathrm{min}$. The benefit seen was largely a reduction in hospitalisation for heart failure, but a post hoc analysis suggested that there may be a survival benefit for patients with a resting heart rate $\geq 75 / \mathrm{min}^{22}$

A single technology assessment of ivabradine by $\mathrm{NICE}^{23}$

${ }^{24}$ recommends ivabradine as an adjunct for patients with a resting heart rate $\geq 75 / \mathrm{min}$ who are already on standard therapy (including appropriate $\beta$ blocker at the maximally tolerated dose), but goes on to suggest that ivabradine should only be started by a heart failure specialist. The need for a specialist goes some way to addressing the major concern that ivabradine might come to be seen as an acceptable alternative to $\beta$ blockers when the evidence that $\beta$ blockers improve survival is overwhelming.

The ivabradine discussion highlights the potential importance of heart rate reduction as a therapeutic target. A challenging reinterpretation of the data from the DIG trial suggests that digoxin in patients with heart failure in sinus rhythm had a similar reduction in the endpoint used in the SHIFT study (namely, cardiovascular death or hospitalisation for heart failure) as ivabradine, with the effect being a reduction in hospitalisation rather than an increase in survival. ${ }^{25}$ Although digoxin is very variably used nowadays, it may be that we should be revisiting its use as heart rate-reducing agent.

\section{Aliskiren}

Inhibition of the renin-angiotensin-aldosterone system (RAAS) has been the cornerstone of heart failure management for decades but, although the outlines of the system are well known, the full ramifications of the RAAS are still being uncovered. For example, angiotensin II (Ang II) can be broken down by ACE2 to yield Ang1-7, which itself has biological activity. ${ }^{26}$ There are many potential targets for treatment becoming available. One potential target has been the initial step in the cascade

-inhibition of the enzymatic activity of renin itself. Aliskiren is a direct renin inhibitor. Early work suggested that it might have a more profound effect on suppressing natriuretic peptide production than standard therapy, ${ }^{27}$ and its ability to avoid any escape from ACE inhibition makes it an attractive agent. However, two trials have cast doubt on its effectiveness. In the ALTITUDE trial, ${ }^{28} 8561$ patients with diabetes, chronic kidney disease, cardiovascular disease or both were randomised to receive aliskiren or placebo in addition to standard therapy. The trial was stopped early after an interim efficacy analysis, and there was a suggestion (although not statistically significant) that aliskiren might be harmful. In the ASTRONAUT study, ${ }^{2930} 1639$ patients were randomised to aliskiren or placebo around 5 days after an index heart failure admission, again in addition to standard therapy. There was no effect on the main outcome measures of cardiovascular death or rehospitalisation with heart failure at 6 and 12 months, but a definite signal that aliskiren might be deleterious in patients with diabetes.
The ATMOSPHERE study ${ }^{31}$ is rather different. It is a study of patients with chronic heart failure due to left ventricular systolic dysfunction and a raised natriuretic peptide level. Patients are randomised to aliskiren, enalapril or both. Fewer patients have diabetes (around a third), and renal function is considerably less impaired in patients in the ATMOSPHERE trial than in those in the ALTITUDE study. ${ }^{32}$ The results of the ATMOSPHERE trial should give a much more profound understanding of the possible role of aliskiren: it is surely possible that it might have a role as an alternative to conventional RAAS blockade rather than as an add-on.

\section{Aldosterone antagonists}

The problem of heart failure with a normal ejection fraction (HeFNEF) remains tricky. It has proved a difficult entity to define clinically despite its apparent frequency in epidemiological studies, and no clinical trial has yet shown any convincing benefit from any treatment strategy. Another disappointment is spironolactone. In patients with heart failure due to left ventricular systolic dysfunction, there is no doubt that mineralocorticoid antagonists help improve cardiac function, symptoms and survival. ${ }^{33}$ Mineralocorticoid antagonists

might be thought to be particularly likely to work in HeFNEF through their antifibrotic properties. However, in the Aldo-DHF study conducted in 422 patients with HeFNEF, spironolactone had no effect on exercise capacity, symptoms or quality of life. ${ }^{34}$ The mean N-terminal prohormone of brain natriuretic peptide level in the patients included in the study was only $158 \mathrm{ng} / \mathrm{L}$, suggesting that yet again a trial of HeFNEF has included patients who really do not have heart failure or, if they do, they are patients with an intrinsically good prognosis.

\section{Device Therapy and Monitoring}

\section{Remote monitoring}

There has been a great deal of enthusiasm for telemonitoring, particularly among commissioners who see it as a way of reducing admissions to hospital among patients with chronic disease. The role of remote monitoring for patients with heart failure has been much debated. Although early studies suggested that there might be a major benefit, more recent trials have been much less positive, perhaps because the background standard of care against which telemonitoring is being compared has improved.

It might be that targeted intensive monitoring during periods of high risk, such as immediately after hospital discharge, makes the best use of remote monitoring. In a meta-analysis of trials involving over 6000 patients, Pandor et $\mathrm{al}^{35}$ found that remote monitoring following an admission with heart failure was associated with improved survival, particularly where usual care was less good.

\section{Defibrillators}

It is commonly thought that having discharges from an implantable cardioverter-defibrillator (ICD), whether 
appropriate or inappropriate, is associated with an adverse prognosis in patients with heart failure. ${ }^{36}$ The commonest reason for an inappropriate shock is atrial fibrillation with a rapid ventricular response; additionally, it is becoming increasingly apparent that antitachycardia pacing may treat ventricular tachycardia without a shock being necessary. The MADIT-RIT trial ${ }^{37}$ reported that programming techniques that both increase antitachycardia pacing and delay ICD discharges reduce the risk of inappropriate discharge. There was a reduction in all-cause mortality of around a half in the advanced programming group.

Intriguingly, in a cohort study of 1698 patients, Deyell et $\mathrm{al}^{38}$ found no association between inappropriate ICD shock and an adverse outcome. In contrast, an appropriate shock was associated with a HR of 3.11 for the combined endpoint of death and transplantation. The reasons for the discrepancy are not clear: it may be related to the fact that the patients in Deyell et al's cohort were less severely symptomatic and were more likely to be on $\beta$ blocker therapy. However, regardless of the prognostic implications, by reducing inappropriate shocks, advanced programming of ICDs improves patients' quality of life by reducing the risk of a very unpleasant ICD discharge.

\section{Cardiac resynchronisation therapy}

The other major device for heart failure is, of course, the cardiac synchronisation therapy (CRT) pacemaker. Although it has been proved to increase life expectancy in patients with heart failure due to left ventricular systolic dysfunction, sinus rhythm and left bundle branch block, controversies remain. Many are convinced that patients in atrial fibrillation or other forms of conduction defect might benefit, although there is no evidence from randomised trials to support these beliefs. ${ }^{39}{ }^{40} \mathrm{~A}$ particular recurring theme is the concept of 'response': around a third of patients are said not to respond to CRT based on either their symptom status or some echocardiographic index of left ventricular function. The subtext is that there might be some patients with conventional indications for CRT who perhaps should be denied the treatment, and others with no indication who might benefit based on some measure of so-called dyssynchrony preoperatively.

As Witte points out, ${ }^{41}$ deactivating a CRT device in a supposed 'non-responder' results in haemodynamic worsening. ${ }^{42}$ Defining 'response' in terms of symptomatic change, or worse, a surrogate measure such as left ventricular volume, is doomed to fail-we cannot know what would otherwise have happened to the patient without the device. One interesting new piece of information is that there appears to be an inverse relation between the duration of heart failure symptoms prior to CRT implantation and subsequent survival, particularly in those with abnormal renal function. ${ }^{43}$ This finding is surely expected: the earlier in the natural history of illness we intervene, the greater is the likely effect. However, it does highlight the need to think about implanting CRT in patients with less severe symptoms if they have left bundle branch block, ${ }^{44}$ rather than waiting until patients are worse but may have less to gain. Further encouragement for earlier CRT implantation comes from the BLOCK-HF study in which patients with impaired left ventricular systolic function and a conventional indication for pacing in the shape of atrioventricular block were studied. ${ }^{45} \mathrm{All}$ the patients had a CRT device implanted, but they were randomised later to conventional dual chamber pacing or biventricular pacing. Nearly 700 patients were included, and the average left ventricular ejection fraction was as high as $40 \%$. None had a conventional indication for CRT. Those receiving active CRT pacing had a reduction in the primary endpoint of all-cause mortality, heart failure-related urgent care or a $>15 \%$ increase in left ventricular endsystolic volume.

\section{Vagal stimulation}

A fascinating new device for patients with chronic heart failure is the vagal stimulator, which might potentially be combined with existing devices. ${ }^{46}$ Patients with chronic heart failure commonly have an imbalance between their enhanced sympathetic nervous system activity and a decline in parasympathetic activity. The vagal stimulator delivers electrical stimulation to the vagus nerve in the neck, timed to the cardiac cycle. Preliminary work suggested that it might have some effect on exercise capacity and quality of life and left ventricular function. ${ }^{47} \mathrm{~A}$ study of 650 patients is being mounted to assess its effects on all-cause mortality and hospitalisation for heart failure. ${ }^{48}$

\section{End-Stage Heart Failure}

For patients with end-stage heart failure, there has been some controversy as to whether implantable defibrillators should be used. The UK guidelines on referral for heart transplantation ${ }^{49}$ address the issue of use of implantable defibrillators in terms of NICE guidance, and point out that we do not have much information to guide the management of those without ischaemic heart disease. However, patients on cardiac transplant waiting lists are at high risk of sudden death, and in a retrospective observational study of over 1000 patients listed for potential cardiac transplantation, Frölich et al found a marked survival benefit for patients receiving an ICD for primary prevention independent of the aetiology of heart failureonly around one-third of the patients had ischaemic heart disease. ${ }^{50}$ The effect was very much less marked for patients receiving an ICD for secondary prevention. Maybe ICDs should be considered more widely in patients on a transplant waiting list.

Some cells from myocardial biopsy samples cluster together to form cardiospheres which can potentially differentiate into many cell types. In a very small study to demonstrate safety, patients treated with intracoronary cardiosphere-derived cells (CDCs) following myocardial infarction had smaller volumes of scar and larger volumes of viable heart mass than those receiving standard care.${ }^{51} \mathrm{CDCs}$ join a long list of potential sources of stem cells, none of which has really borne fruit despite enormous enthusiasm. 


\section{References}

1 National Heart Failure Audit April 2011-March 2012. National Centre for Cardiovascular Prevention and Outcomes, University College London, 2012. https:// www.ucl.ac.uk/nicor/audits/ heartfailure/additionalfiles/pdfs/annualreports/annual12. pdf

2 Takeda A, Taylor SJ, Taylor RS, et al. Clinical service organisation for heart failure. Cochrane Database Syst Rev 2012;9:CD002752.

3 Holland R, Battersby J, Harvey I, et al. Systematic review of multidisciplinary interventions in heart failure. Heart 2005;91:899-906.

4 Thomas R, Huntley A, Mann M, et al. Specialist clinics for reducing emergency admissions in patients with heart failure: a systematic review and meta-analysis of randomised controlled trials. Heart 2013;99:233-9.

5 National Institute for Health and Care Excellence. Chronic heart failure. Clinical guideline 108. London, 2010.

6 Al-Mohammad A, Mant J. The diagnosis and management of chronic heart failure: review following the publication of the NICE guidelines. Heart 2011;97:411-16.

7 National Institute for Health and Care Excellence. Chronic heart failure quality standard: QS9. London, 2011.

8 Heidenreich PA, Albert NM, Allen LA, et al. Forecasting the impact of heart failure in the United States: a policy statement from the American Heart Association. Circ Heart Fail 2013;6:606-19.

9 Mostofsky E, Rice MS, Levitan EB, et al. Habitual coffee consumption and risk of heart failure: a dose-response meta-analysis. Circ Heart Fail 2012;5:401-5.

10 McMurray JJ, Adamopoulos S, Anker SD, et al. ESC guidelines for the diagnosis and treatment of acute and chronic heart failure 2012: The Task Force for the Diagnosis and Treatment of Acute and Chronic Heart Failure 2012 of the European Society of Cardiology. Developed in collaboration with the Heart Failure Association (HFA) of the ESC. Eur Heart J 2012;33:1787-847.

11 Shah AS, Langrish JP, Nair H, et al. Global association of air pollution and heart failure: a systematic review and meta-analysis. Lancet. Published Online First: 9 July 2013. doi:10.1016/ S0140-6736(08)61345-8

12 Aliti GB, Rabelo ER, Clausell N, et al. Aggressive fluid and sodium restriction in acute decompensated heart failure a randomized clinical trial. JAMA Intern Med 2013;173:1058-64.

13 Costanzo MR, Guglin ME, Saltzberg MT, et al. Ultrafiltration versus intravenous diuretics for patients hospitalized for acute decompensated heart failure. J Am Coll Cardiol 2007;49:675-83.

14 Teerlink JR, Metra M, Felker GM, et al. Relaxin for the treatment of patients with acute heart failure (Pre RELAX AHF): a multicentre, randomised, placebo-controlled, parallel-group, dosefinding phase Ilb study. Lancet 2009;373:1429-39.

15 Teerlink JR, Cotter G, Davison BA, et al. Serelaxin, recombinant human relaxin-2, for treatment of acute heart failure (RELAX-AHF): a randomised, placebo-controlled trial. Lancet 2013;381:29-39.

16 http://www.novartis.com/newsroom/media-releases/ en/2013/1711047.shtml (accessed 2 Jul 2013).

17 Solomon SD, Zile M, Pieske B, et al. The angiotensin receptor neprilysin inhibitor LCZ696 in heart failure with preserved ejection fraction: a phase 2 double-blind randomised controlled trial. Lancet 2012;380:1387-95.

18 Cleland JG, Clark AL. Heart failure-does it matter whether LVEF is reduced? Lancet 2012;80:1363-5.

19 Packer M, Colucci W, Fisher L, et al. Effect of levosimendan on the short-term clinical course of patients with acutely decompensated heart failure. JACC Heart Fail 2013;1:103-11.

20 Goldacre B. Are clinical trial data shared sufficiently today? No. BMJ 2013;347:f1880.

21 Swedberg K, Komajda M, Böhm M, et al. Ivabradine and outcomes in chronic heart failure (SHIFT): a randomised placebocontrolled study. Lancet 2010;376:875-85.

22 Böhm M, Borer J, Ford I, et al. Heart rate at baseline influences the effect of ivabradine on cardiovascular outcomes in chronic heart failure: analysis from the SHIFT study. Clin Res Cardiol 2013;102:11-22.

23 National Institute for Health and Care Excellence. Ivabradine in chronic heart failure. 2012. http://www.nice.org.uk/TA267

24 Hardman SM. Ivabradine in heart failure: NICE guidance. Heart. Published Online First: 18 June 2013. http://heart.bmj.com/con- tent/early/2013/06/17/heartjnl-2012-303490.full. pdf+html?sid=29e1ec6a-5827-4d48-95ac-87be0a60b7c6

25 Castagno D, Petrie MC, Claggett B, et al. Should we SHIFT our thinking about digoxin? Observations on ivabradine and heart rate reduction in heart failure. Eur Heart J 2012;33:1137-41.

26 Chemaly ER, Hajjar RJ, Lipskaia L. Molecular targets of current and prospective heart failure therapies. Heart 2013;99:992-1003.

27 McMurray JJ, Pitt B, Latini R, et al. Effects of the oral direct renin inhibitor aliskiren in patients with symptomatic heart failure. Circ Heart Fail 2008;1:17-24.

28 Parving $\mathrm{HH}$, Brenner BM, McMurray JJ, et al. Cardiorenal end points in a trial of aliskiren for type 2 diabetes. $\mathrm{N}$ Engl J Med 2012;367:2204-13.

29 Gheorghiade M, Albaghdadi M, Zannad F, et al. Rationale and design of the multicentre, randomized, double-blind, placebocontrolled Aliskiren Trial on Acute Heart Failure Outcomes (ASTRONAUT). Eur J Heart Fail 2011;13:100-6.

30 Gheorghiade M, Böhm M, Greene SJ, et al. Effect of aliskiren on postdischarge mortality and heart failure readmissions among patients hospitalized for heart failure: the ASTRONAUT randomized trial. JAMA 2013;309:1125-35.

31 Krum H, Massie B, Abraham WT, et al. Direct renin inhibition in addition to or as an alternative to angiotensin converting enzyme inhibition in patients with chronic systolic heart failure: rationale and design of the Aliskiren Trial to Minimize OutcomeS in Patients with HEart failuRE (ATMOSPHERE) study. Eur J Heart Fail 2011;13:107-14.

32 McMurray JJ, Abraham WT, Dickstein K, et al. ALTITUDE, and the implications for ATMOSPHERE. Eur J Heart Fail 2012;14:341-3.

33 Phelan $D$, Thavendiranathan $\mathrm{P}$, Collier $\mathrm{P}$, et al. Aldosterone antagonists improve ejection fraction and functional capacity independently of functional class: a meta-analysis of randomised controlled trials. Heart 2012;98:1693-700.

34 Edelmann F, Wachter R, Schmidt AG, et al. Effect of spironolactone on diastolic function and exercise capacity in patients with heart failure with preserved ejection fraction: the Aldo-DHF randomized controlled trial. JAMA 2013;309:781-91.

35 Pandor A, Gomersall T, Stevens JW, et al. Remote monitoring after recent hospital discharge in patients with heart failure: $a$ systematic review and network metaanalysis. Heart.Published Online First: 16 May 2013. http://heart.bmj.com/content/ earI y / 2013 / 05 / 15/heartjn I-2013-303811.ful| . pdf+html?sid=25776cbc-1e08-4e6f-abc1-638828de7d98

36 Poole JE, Johnson GW, Hellkamp AS, et al. Prognostic importance of defibrillator shocks in patients with heart failure. N Engl J Med 2008;359:1009-17.

37 Moss AJ, Schuger C, Beck CA, et al. Reduction in inappropriate therapy and mortality through ICD programming. N Engl J Med 2012;367:2275-83.

38 Deyell MW, Qi A, Chakrabarti S, et al. Prognostic impact of inappropriate defibrillator shocks in a population cohort. Heart 2013;99:1250-5.

39 Hawkins NM, Petrie MC, Burgess MI, et al. Selecting patients for cardiac resynchronization therapy: the fallacy of echocardiographic dyssynchrony. J Am Coll Cardiol 2009;53:1944-59.

40 Tang AS, Wells GA, Talajic M, et al. Cardiac-resynchronization therapy for mild-to-moderate heart failure. N Engl J Med 2010;363:2385-95.

41 Witte KK. Cardiac resynchronisation therapy for chronic heart failure: predicting and measuring 'response'. Heart 2013;99:293-4.

42 Mullens W, Verga T, Grimm RA, et al. Persistent hemodynamic benefits of cardiac resynchronization therapy with disease progression in advanced heart failure. J Am Coll Cardiol 2009;53:600-7.

43 Verbrugge FH, Dupont M, Vercammen J, et al. Time from emerging heart failure symptoms to cardiac resynchronisation therapy: impact on clinical response. Heart 2013;99:314-19.

44 Yancy CW, Jessup M, Bozkurt B, et al. 2013 ACCF/AHA Guideline for the Management of Heart Failure: A Report of the American College of Cardiology Foundation/American Heart Association Task Force on Practice Guidelines. Circulation. Published Online First: 5 June 2013. http://circ.ahajournals.org/content/ early/2013/06/03/CIR.0b013e31829e8776.long 
45 Curtis AB, Worley SJ, Adamson PB, et al. Biventricular versus Right Ventricular Pacing in Heart Failure Patients with Atrioventricular Block (BLOCK HF) Trial Investigators. Biventricular pacing for atrioventricular block and systolic dysfunction. N Engl J Med 2013;368:1585-93.

46 Schwartz PJ. Vagal stimulation for the treatment of heart failure: a translational success story. Heart 2012;98:1687-9.

47 Schwartz PJ, De Ferrari GM, Sanzo A, et al. Long term vagal stimulation in patients with advanced heart failure: first experience in man. Eur J Heart Fail 2008;10:884-91.

48 Hauptman PJ, Schwartz PJ, Gold MR, et al. Rationale and study design of the increase of vagal tone in heart failure study: INOVATE-HF. Am Heart J 2012;163:954-62.
49 Banner NR, Bonser RS, Clark AL, et al. UK guidelines for referral and assessment of adults for heart transplantation. Heart 2011;97:1520-7.

50 Fröhlich GM, Holzmeister J, Hübler M, et al. Prophylactic implantable cardioverter defibrillator treatment in patients with end-stage heart failure awaiting heart transplantation. Heart 2013;99:1158-65.

51 Makkar RR, Smith RR, Cheng K, et al. Intracoronary cardiospherederived cells for heart regeneration after myocardial infarction (CADUCEUS): a prospective, randomised phase 1 trial. Lancet 2012;379:895-904. 